комплексних методів залучення молоді до систематичних занять оздоровчими фізичними вправами та спортом для досягнення професійних спортивних здобутків.

\title{
Література:
}

1. Дзензелюк Д. Роль мотивації студентів до занять фізичними вправами на заняттях фізичного виховання у вищих навчальних закладах // Спортивна наука України, 2013. - № 6 (57). - С. 50 - 55.

2. Ефремова А.Я., Сапегіна I.О., Довженко С.С., Кочеткова Т.М. Формування мотиваційної сфери до здорового пособу життя і занять фізичною культурою у майбутніх інженерів залізничного транспорту. Електронний pecypc. Режим доступу : http://www.sworld.com.ua/index.php/uk/physicaleducation-and-sport-411/physical-education-physical-education-different-groups411/11761-411-0803

3. Жуковський Є.I. Формування у студентів мотивації до самостійної фізкультурно-оздоровчої діяльності. Електронний ресурс. Режим доступу : http://eprints.zu.edu.ua/12800/1/\%D1\%84\%D0\%BE $\%$ D $1 \% 80 \% \mathrm{D} 0 \% \mathrm{BC} \% \mathrm{D} 1 \% 83 \%$ D0\%B2.pdf

4. Корж Н.Л. Формування ціннісного ставлення у студентів до фізичної культури в процесі самостійних занять // Дисертація на здобуття наукового ступеня кандидата наук 3 фізичного виховання та спорту. Дніпропетровськ, 2016. - 269 с. Електронний ресурс. Режим доступу : http://www.infiz.dp.ua/joomla/images/docum/spec-rada/zah0014-2016-12-17-dissert$\underline{01 . p d f}$

5. Марченко О.Ю. Формування фізичної культури студентів у процесі навчання у вищих навчальних закладах / О. Ю. Марченко // Теорія і методика фізичного виховання і спорту. - 2008. - №2. - С. 82 - 84.

6. Повар О. Мотиваційно-ціннісне ставлення студентів університетів до фізичного виховання й спорту // Фізичне виховання, спорт і культура здоров'я у сучасному суспільстві : збірник наукових праць, 2012. - №. 1 (17). - С. 50 - 55.

Стаття відправлена: 08.06.2017 p.

(C) Шуст O.M., Конопляник О.В.

\section{ЦИТ: иа217-029}

DOI: 10.21893/2415-7538.2017-06-3-029

УДК 165.2

Карачунский В.A.

БИОЛОГИЧЕСКАЯ СУЩНОСТЬ МЕХАНИЧЕСКОЙ ФОРМЫ ДВИЖЕНИЯ

BIOLOGICAL SENSE OF MECHANICAL FORM OF MOVEMENT

Karachunskiy V.A

Приазовский государственный технический университет, Мариуполь, ул. Университетская 7, 87500

Priazovskij gosudarstvennyj tehnicheskij universitet, Mariupol', ul. Universitetskaja 7, 87500

Аннотачия. С биологической точки зрения источником представлений о 
механическом движении является активность мышечной системы, которая проявляется как поведение субъекта во внешней среде и как процесс мыпления в сознании. Первичное представление о механическом перемещуении объекта это проекция в сознание сложных прочессов окружающего пространства, которые нельзя считать элементарной формой движения. Наше сознание воспринимает не механизм изменений внешней среды, а возможность мьшиечной системы противодействовать этим изменениям и только в этом плане механическое движение является элементарным.

Ключевые слова: механическое движение, мышечная система, сознание

Вступление.

При написании данной статьи использован идеальный способ анализа феномена «механическое движение», основанный на понимании того, что в первую очередь окружающий мир является нашим сознанием и только во вторую объективной реальностью. Такой способ рассмотрения действительности широко применялся на всех этапах развития философии и получил свое классическое обоснование в работах Беркли и Гегеля [1]. Тем не менее, принцип «физическое есть ментальное», при всей своей убедительности, не нашел должного развития, поскольку противопоставлялся материалистическому мировоззрению. Попытка решения данной проблемы было предложена автором данной статьи в монографии «Философия движения» (изд. ПГТУ, 2003), где идеализм и материализм понимались как два способа описания виртуального пространства. Согласно полученным выводам, идеалист располагает свое «Я» в сознании субъекта и воспринимает виртуальное пространство как продукт действия внешних сил, то есть как движение. Материалист «отчуждает» свое «Я», располагает его в стороне от собственного сознания, при этом невольно воспринимает виртуальное пространство как совокупность материальных тел. Для преодоления дуализма «Я» было предложено рассматривать материю как продукт стабилизации динамических процессов в сознании. Равновесие внешних сил и противодействие им со стороны организма формирует в сознании замкнутую форму движения, устойчивую в пространстве и времени, что собственно и является объяснением материи с динамической точки зрения.

\section{Основной текст}

В парадигме движения существование организма поддерживается равновесием между происходящими в организме процессами и внешними воздействиями. Окружающий нас мир и все происходящие в нем явления это динамическая система, первично созданная в сознании действием внешних сил. Средой для существования сознания является сеть нейронов, в которую через рецепторы поступают потоки энергии, как от внешней среды, так и от внутренней среды организма. Как следствие, в нейронной сети организма присутствуют две динамические системы, которые взаимодействуют между собой - «модель внешней среды» и «модель организма». Как следствие, если в процессе адаптации достигается равновесие между организмом и внешней средой, это приводит к появлению в нейронной сети устойчивых в пространстве и времени кольцевых потоков импульсов (кольца реверберации), 
которые собственно и являются сознанием с точки зрения нейрофизиологии [2]. Поскольку «модель организма» в нейронной сети представлена в основном проекцией различных участков мышечной системы, которые суммарно воспринимаются как ощущение нашего «Я», направленность процесса мышления в сознании отражает становление равновесия между мышечной системой организма с внешней средой. Таким образом, проявление мышечной активности в сознании становится системообразующим фактором построения виртуального пространства.

Концепцию происхождения мышления, как проекции активности мышечной системы в сознание, убедительно доказывают материалы нейрофизиологических исследований, причем поведение организма в среде обитания, в этом контексте, так же следует рассматривать как форму мышления. В мозге человека существуют две относительно самостоятельные области управления мышечным движением, первая и вторая сигнальные системы, соответственно с которыми формируются две формы мышления мышление внешнее и мышление внутреннее [3]. Первая сигнальная система является древней структурой мозга, которая на неосознанном уровне (автоматически) реализует опыт поколений. Процесс формирования первой сигнальной системы у примитивных организмов происходит методом проб и ошибок в процессе взаимодействия с внешней средой, без участия сознания в привычном для нас понимании, о чем свидетельствуют данные сравнительной психофизиологии и экспериментально выявленные закономерности формирования механизмов памяти в нейронных сетях [4]. Поведенческую активность организма можно рассматривать как своеобразное внешнее мышление («ручное мышление обезьян» по Павлову), которое позволяет мышечной системе адаптироваться к среде обитания и в этом плане необходимо отметить, если поведение организма уравновешивает внешние воздействия, то в нем невольно отражаются законы природы. Как показывает нейрофизиология когнитивных процессов, появление у высокоразвитых организмов достаточно развитой сенсорной коры сопровождается формированием в ней виртуальной модели внешней среды, которая посредством моторной коры взаимодействует с мышечной системой (вторая сигнальная система) [5]. Процесс мышления, в привычном для нас представлении, это волна возбуждения в моторной коре, вызванная активностью специализированных участков мышечной системы, которая перемещается по нейронной сети и активирует определенные области мозга («луч прожектора» по замечанию И.П. Павлова) [6 С. 204]. Вторая сигнальная система позволяет организму «мыслить» без непосредственного контакта с природой, поскольку мышечная активность организма направлена на виртуальную модель природы в сознании. Таким образом, вторая сигнальная система использует опыт первой сигнальной системы для создания программ поведения, но уже не в настоящем, а в будущем времени. Основополагающую роль мышечной системы в формировании процесса мышления неоднократно доказывал в своих работах И.М. Сеченов, которому принадлежит известное выражение «мысль - это рефлекс с задержанным концом» [7]. 
В этом контексте становиться понятным, почему все изменения, происходящие в окружающем мире, рано или поздно получают объяснение с точки зрения механического движения. Например, восприятие нами зрительных, обонятельных и слуховых образов происходит раздельно, что заложено как природой данных процессов, так и особенностями рецепторов нервной системы, которые на них реагируют. Тем не менее, несмотря на различие характера первичных ощущений, наше мышление находит им механическое объяснение. Восприятие звука рассматривается как вибрации воздуха, обоняние получает «механическое» объяснение как распространение молекул вещества в воздушной среде и как соединение их с поверхностью рецептора. «Механически», как действие фотона на рецепторы сетчатки глаза, объясняется зрительное восприятие. Аналогичные закономерности имеют место при научном объяснении физических и химических явлений в окружающей нас действительности (квантово-механическая теория строения материи). Иными словами, процесс познания, с биологической точки зрения, это переформатирование всех форм воздействий внешней среды на организм субъекта на язык механики, что позволяет мышечной системе организма противодействовать внешней среде.

Подобное понимание мышления позволяет прийти к выводу, что кора мозга не имеет ведущего значения в управлении организмом человека, несмотря на широкую распространенность подобной точки зрения. Кора помогает более эффективно решать задачи, поставленные перед ней подкоркой, которая в свою очередь, методом проб и ошибок, находит равновесие с окружающей действительностью и в этом плане следует отметить справедливость утверждения Гегеля, который считал, что законы мышлении и законы природы имеют единое происхождение. В процессе эволюции организма, именно активность мышечной ткани, сначала в форме поведения, а потом в форме мышления, становится основной его взаимодействия с внешней средой. В этом контексте, научная картина мира является механической моделью взаимодействия субъекта с окружающей действительностью (несмотря на кажущуюся парадоксальность подобного предположения). По мере развития науки в сознании происходит переформатирование физических, химических, биологических и прочих явлений природы на язык мышечной активности, что постоянно увеличивает власть человека над природой. Если рассматривать познание с точки зрения эволюции сознания как динамической системы, то критерием объективности внешнего мира становиться движение образов сознания, а не особенности их субъективного восприятия, на что в свое время не обратил внимание Д Беркли.

В основе современных представлений о формах движения лежит классификация, предложенная Ф. Энгельсом в «Диалектике природы», которая в определенной мере повторяет градацию форм движения Гегеля в «Науке логики» [8]. Следует обратить внимание, различие в понимании движения у Энгельса и Гегеля обусловлено положением «Я» в системе их рассуждений. Гегель располагает свое «Я» в сознании субъекта, поэтому бытие воспринимается им через «призму сознания», как действие внешних сил. 
Понимание механического движения у Гегеля происходит на интуитивном уровне, как проявление абсолютной идеи (системообразующего фактора) в перемещении объектов природы и образов сознания в процессе мышления. Энгельс анализирует бытие иначе, позиционирует себя в качестве объективного наблюдателя в стороне от собственного сознания-бытия и одновременно интуитивно понимает себя как часть бытия, то есть происходит своеобразное раздвоение «Я» на «объективного наблюдателя» и «субъекта в природе». Для внешнего наблюдателя существование материи (элемента движения) является аксиомой, поэтому Энгельс, принимая идею всеобщего движения, начинает рассматривать движение как атрибут материи, соответственно классификация форм движения переформатируется в классификацию форм материи:

- Механическое движение

- Группа физических форм движения

- Химическое движение

-Биологическое движение

- Социальное движение

Необходимо обратить внимание, именно двойственность положения «Я» относительно сознания-бытия приводит к появлению двух способов его рассмотрения - материализма и идеализма. Примером анализа процесса познания материалистическим способом, является философия Ф. Бэкона. Предложенный им метод индукции ставит во главу познания внешнюю активность субъекта, который в процессе эксперимента изучает определенные стороны окружающего мира, объединяет полученные факты и формирует в сознании модель фрагмента действительности [9]. Иными словами, субъект рассматривает себя со стороны как объект, который взаимодействует с окружающей средой. Диаметрально противоположный подход имеет место в дедукции, когда отдельные факты, полученные в различное время и в разных областях знания, объединяются в единую систему в виртуальном пространстве. В процессе дедукции субъект располагает свое «Я» в сознании, временно игнорируя существование внешнего мира. Понимание двойственности позиции «Я» в сознании, позволяет рассматривать материализм и идеализм, по аналогии с индукцией и дедукцией, как два способа анализа бытия, которые дополняют друг друга. Традиционное противопоставление материализма и идеализма порождает в каждом направлении философии неразрешимые проблемы. Например, материальный подход предполагает существование элемента движения, то есть материи без движения, а идеальный подход не может объяснить, чем с точки зрения движения является материя.

Без понимания биологического происхождения феномена «механическое движение», определить его место в системе всеобщего движения затруднительно. Энгельс рассматривал механическое движение с материалистической точки зрения, как атрибут элементарной формы материи. Гегель механическое движение анализировал в контексте мышления, источником которого является внешняя причина - мировой разум. Оба способа рассуждения, материальный и идеальный противопоставлялись друг другу и 
предполагали существование механического движения как самостоятельного феномена в природе (элементарная форма движения и мировой разум). С биологической точки зрения, механическое движение это этап развития природы, точка отсчета во взаимодействии организма и окружающей средой. Предложенная в данной статье биологическая концепция механического движения использует идеальный способ рассуждения, поскольку располагает «Я» в центре изучаемой системы, но идеальная точка зрения предполагает существование механического движения вне организма субъекта, а биологическая точка зрения показывает механическое движение как свойство организма. С биологической точки зрения, градация форм движения привязана к процессу познания:

- Мышечная активность - осознание собственного «Я»

- Механическое движение - поведенческая активность организма и мысленное перемещение объектов в виртуальном пространстве

- Социальное движение - активность субъекта в социуме

- Биологическое движение - теоретический анализ и взаимодействие с живой природой

- Химическое движение - теория и практика анализа дискретности материи

- Физическое движение - понимание материи в контексте динамической системы

Предложенная Ф. Энгельсом классификация форм движения получила наиболее последовательное развитие в советской школе философии. Основой различения форм движения в диамате являлась теоретическая модель материального мира, где каждая отрасль знания занималась собственным сегментом, которому соответствовала определенная форма движения. Например, предлагалось введение космологической (Б.Я. Пахомов, И.Д. Панцхава), кибернетической (Б.М. Кедров, 1961), ландшафтной (Л.Н. Самойлов), географической (А.А. Григорьев, 1932), геологической (Б.М. Кедров, 1947) и других форм движения. Например, Б.Я. Пахомов утверждает: «В глобальных масштабах конечным результатом развития выступает возникновение иерархии структурных уровней материи и соответствующих форм движения. Следовательно, развитие и есть процесс возникновения предпосылок, а затем и образования иерархии структурных уровней материи и форм её движения» [10]. Аналогичную точку зрения находим у Б.М. Кедрова: «Для более полной характеристики взглядов Энгельса на формы движения материи нужно отметить одно исключительно важное обстоятельство. Каждую форму движения он сопоставляет с присущим ей особым материальным носителем - видом материи, способом существования которого является данная форма движения» [11]. Как было показано на примере механического движения, такой подход выводит биологические формы движения за пределы сознания и это порождает цепную реакцию неопределенностей в системе рассуждений. Новые формы материи образуются в результате познания, по мере объяснения явлений их сущности с механической точки зрения. 


\section{Заключение и выводы.}

В науке принято рассматривать движение материалистическим способом, как атрибут развития материи, при этом становиться незаметным тот факт, что представление о развитии материального мира дано нам на языке сознания. С точки зрения сознания, «бытие» есть определенный этап развития биологического уровня движения, где появление механического движения связано с формированием мышечной системы, которая становиться основным способом взаимодействия многоклеточных организмов с окружающей средой. Проекция активности мышечной системы в сознание - процесс мышления, становиться точкой отсчета в познании окружающего мира и это объясняет его элементарность. Подобное понимание природы механического движения помогает правильно расставить акценты в некоторых вопросах теории мышления, логики, математики, методики установления критерия истины.

Литература:

1. Асмус В.Ф. Беркли // БСЭ, т. 3. - М.: Советская энциклопедия, 1970. - с. $695-696$.

2. Батуев А.С. Физиология высшей нервной деятельности и сенсорных систем. - СПб.: Питер, 2006. - 317 с.

3. Анохин П.К. Павлов И.П. // Большая советская энциклопедия. М.: «Советская энциклопедия», т. 19. 1975. С. 176 - 179.

4. Гаврилов В.В. Сравнительная психофизиология // Психофизиология. Под ред. Ю.И. Александрова. СПб.: Питер, 2007. С. 373 - 384.

5. Кэндел Э. Клеточные основы поведения. М.: Мир, 1980. 598 с.

6. Иваницкий А.M. Психофизиология сознания // Основы психофизиологии, гл. 11. М.: ИНФРА-М, 1998. С. $202-219$.

7. Сеченов И.М. Физиология высшей нервной деятельности // Избранные произведения Т.2. М.: Изд-во Академии наук СССР, 1956. 940 с.

8. Энгельс Ф. Диалектика природы. М.: Изд-во ЦК ВКП(б), 1934. 300 с.

9. Румянцева Т.Г. Бекон Ф. // Всемирная энциклопедия: Философия. М.: АСТ Мн.:Харвест, Современный литератор 2001. С. 147 - 149.

10. Пахомов Б.Я. Эволюция - развитие - структурные уровни материи // Труды III всесоюзного совещания по философским вопросам современного естествознания. М.: Наука, 1983. С. 243-246.

11. Кедров Б.М. Критерии различения высших и низших форм движения материи // Пространство, время, движение. Диалектический материализм и современное естествознание. М.: Наука, 1971. С. 326-343.

\section{Abstract}

Mechanical movement turns up a muscles activity language, a universal collaborative mechanism of environments and organism. Muscles activity projection onto the person consciousness allows to create behavioral programs in the future. From this point of view we can consider cognitive process as mechanical explanation of natural phenomena which offers opportunities for its actual use. The unilateral conception of mechanical movement in materialism and idealism erroneously posits it above the person. For example Hegel is considering mechanical movement in the context of thinking as the universal intellect projection. And Engels is assuming the existence of mechanical movement in the nature independently of person.

Key words: mechanical movement, muscle system, consciousness. 
References:

1. Asmus V.F. Berkli // BSJe, t. 3. - M.: Sovetskaja jenciklopedija, 1970. - s. 695 - 696.

2. Batuev A.S. Fiziologija vysshej nervnoj dejatel'nosti i sensornyh sistem. - SPb.: Piter, 2006. $-317 \mathrm{~s}$.

3. Anohin P.K. Pavlov I.P. // Bol'shaja sovetskaja jenciklopedija. M.: «Sovetskaja jenciklopedija», t. 19. 1975. S. $176-179$.

4. Gavrilov V.V. Sravnitel'naja psihofiziologija // Psihofiziologija. Pod red. Ju.I. Aleksandrova. SPb.: Piter, 2007. S. 373 - 384.

5. Kjendel Je. Kletochnye osnovy povedenija. M.: Mir, 1980. 598 s.

6. Ivanickij A.M. Psihofiziologija soznanija // Osnovy psihofiziologii, gl. 11. M.: INFRA-M, 1998. S. $202-219$.

7. Sechenov I.M. Fiziologija vysshej nervnoj dejatel'nosti // Izbrannye proizvedenija T.2. M.: Izd-vo Akademii nauk SSSR, 1956. $940 \mathrm{~s}$.

8. Jengel's F. Dialektika prirody. M.: Izd-vo CK VKP(b), 1934. 300 s.

9. Rumjanceva T.G. Bekon F. // Vsemirnaja jenciklopedija: Filosofija. M.: AST Mn.:Harvest, Sovremennyj literator 2001. S. $147-149$.

10. Pahomov B.Ja. Jevoljucija - razvitie - strukturnye urovni materii // Trudy III vsesojuznogo soveshhanija po filosofskim voprosam sovremennogo estestvoznanija. M.: Nauka, 1983. S. 243-246.

11. Kedrov B.M. Kriterii razlichenija vysshih i nizshih form dvizhenija materii // Prostranstvo, vremja, dvizhenie. Dialekticheskij materializm i sovremennoe estestvoznanie. M.: Nauka, 1971. S. 326-343.

Статья отправлена: 24.05.2017 г.

(C) Карачунский В.А.

ЦИТ: иа217-055

DOI: 10.21893/2415-7538.2017-06-3-055

Халявка Л.В

КОНЦЕПТ УКРАЇНА В АНГЛОМОВНОМУ ПУБЛЦИСТИЧНОМУ ДИСКУРСІ

Полтавський національний педагогічний університет імені В.Г.Короленка Lidiia Khaliavka

THE CONCEPT UKRAINE IN THE ENGLISH JOURNALISTIC DISCOURSE

У статті розглядається особливості використання концепту УКРАЇНА в англомовному публіцистичному дискурсі в контексті лінгвопрагматичного аналізу. Актуальність дослідження полягає в аналізі арсеналу лінгвістичних засобів, якими користуються журналісти, публічисти, та ролі изих засобів у формуванні іміджу України з метою свідомого та несвідомого сугестивного впливу на читача.

Ключові слова: концепт, метафора, поле, сфера-джерело, картина світу, тематичні блоки.

The article deals with peculiarities of using concept UKRAINE in Englishlanguage journalistic discourse in the context of linguistic pragmatic analysis. Relevance of the research consists in the analysis of linguistic arsenal of means, which are used by journalists, publicists, and the role of these ones in shaping the image of Ukraine for the purpose of of conscious and unconscious suggestive 